\title{
Late presentation of Nipah virus encephalitis and kinetics of the humoral immune response
}

\author{
S C Wong, M H Ooi, M N L Wong, P H Tio, T Solomon, M J Cardosa
}

\begin{abstract}
Nipah virus is a newly discovered paramyxovirus transmitted directly from pigs to humans. During a large encephalitis outbreak in Malaysia and Singapore in 1998-9, most patients presented acutely. A 12 year old child is described who developed encephalitis 4 months after exposure to the virus. She was diagnosed by a new indirect IgG enzyme linked immunosorbent assay (ELISA), which is also described. The late presentation and IgG subclass responses had similarities to subacute sclerosing panencephalitis. Nipah virus should be considered in patients with encephalitis even months after their possible exposure.

(F Neurol Neurosurg Psychiatry 2001;71:552-554)
\end{abstract}

Keywords: Nipah virus; encephalitis; diagnosis

Between September 1998 and June 1999, an outbreak of severe viral encephalitis occurred in peninsular Malaysia and Singapore, caused by the newly discovered Nipah virus. ${ }^{12}$ This paramyxovirus, closely related to Hendra virus, ${ }^{3}$ caused illness in pigs, and humans in close contact with pigs or their secretions, such as farmers and abattoir workers. During the outbreak, the diagnosis was made by virus isolation from CSF, or by serological tests against Hendra virus, because serological tests for Nipah virus had not yet been developed. ${ }^{4}$ Most patients infected with Nipah virus presented with acute encephalitis, ${ }^{256}$ but three patients had a neurological relapse up to 39 days after an initial mild illness. ${ }^{4}$ We report here a patient who presented with mild Nipah encephalitis 4 months after exposure to the virus; in addition we describe the development of an indirect IgG enzyme linked immunosorbent assay (ELISA) for diagnosing Nipah virus infection, and the IgG subclass responses.

\section{Case report}

A 12 year old girl presented to Sibu hospital, Sarawak in April 1999 with a 2 day history of fever and right frontal headache, and a 5 minute episode of sudden jerking movements of the left leg, which was followed by weakness and numbness of the same limb.

She was born in Sarawak, on the island of Borneo, but had moved with her two sisters and parents to a pig farm in Negeri Sembilan, peninsular Malaysia, in 1997. Her work here included feeding the pigs, artificial insemination of sows, delivering piglets, and injecting sick pigs. In December 1998, when the Nipah virus outbreak reached Negeri Sembilan, her father became ill with encephalitis. In the same week our patient had a 2 day febrile illness with a runny nose, cough, headache, and blurred vision, which resolved spontaneously. In January 1999, after her father's death, she returned to Sarawak with her family. In February she had another brief episode of fever and chills which resolved with paracetamol. Her mother and sisters had remained well throughout. As a child the patient had been immunised with BCG, hepatitis B, oral polio vaccine, measles, diphtheria, pertussis, and tetanus. During the encephalitis outbreak she, along with many others, was vaccinated against Japanese encephalitis virus (JEV).

On examination at Sibu hospital, the patient was apyrexial, and looked well. General medical examination was normal. She was fully conscious, but during the examination developed a further 4 minute episode of rhythmic jerking of the left leg. This limb was weak (power grade $4 / 5$ in all groups), reflexes were normal, but tone was increased in both the left leg and left arm. She had no sensory loss, although she continued to report paraesthesia of the left leg. Over the next few hours her residual weakness and paraesthesia resolved.

Initial investigations including full blood count, urea, electrolytes, and liver function tests, were normal, except for a slightly low sodium concentration at $132 \mathrm{mmol} / \mathrm{l}$. Examination of CSF showed a pleocytosis with 170 cells $/ \mathrm{mm}^{3}$ (100\% lymphocytes), a protein concentration of $82 \mathrm{mg} / \mathrm{dl}$, and a glucose concentration of $48 \mathrm{mg} / \mathrm{dl}$. No organisms were seen and bacterial culture was negative. Brain CT was normal.

Over the next 2 days, the patient had an intermittent mild pyrexia, and two brief episodes of generalised tonic-clonic seizures, which resolved without treatment. After loading with intravenous phenytoin $(10 \mathrm{mg} / \mathrm{kg})$ she had no further convulsions. Because of the CSF pleocytosis she was treated with penicillin and chloramphenicol, but she made an uneventful recovery and was discharged well, 10 days after admission. At 1 week, 1 month, 6 


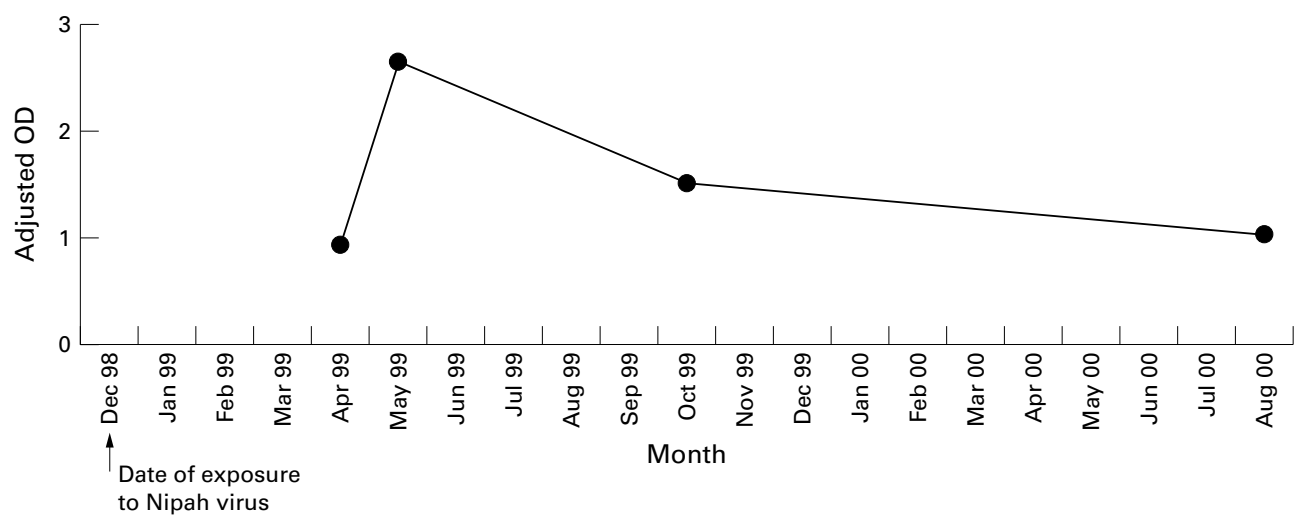

Figure 1 Kinetics of the serum IgG response (dilution 1 in 1000) in a patient with Nipah encephalitis. She was exposed to the virus in December 1998, but developed encephalitis in April 1999.

months, and 1 year follow up she remained well, and was working as a waitress.

VIROLOGICAL INVESTIGATIONS

The patient's CSF and serum were negative for IgM against JEV and dengue viruses. ${ }^{7}$ Serum IgG was strongly positive for JEV at 1:500 dilution, which was consistent with her recent vaccination. Polymerase chain reaction (PCR) of CSF and serum was negative for enteroviruses and adenoviruses. ${ }^{8}$ No virus was isolated. RNA extracted from $50 \mu \mathrm{CSF}$ was subjected to RT PCR using primers for a portion of the $\mathrm{N}$ gene of Nipah virus, ${ }^{9}$ but was negative. The patient's acute and convalescent samples were investigated using an indirect IgG ELISA for antibodies against Nipah virus, which we developed as follows.

DEVELOPMENT OF INDIRECT IGG ELISA

Vero E6 cells were infected with a Nipah virus strain isolated from the pons of a fatal human case in 1998. Nipah virus infected and uninfected Vero cells were lysed using a hypotonic buffer containing $1 \%$ TritonX100, then heat inactivated for 30 minutes at $56^{\circ} \mathrm{C}$ before coating microtitre plates (Maxisorp C bottom, Nalge Nunc International, Rochester, NY, USA) at 1:500 dilution. Lysates were also subjected to RNA extraction and the identity of the virus was confirmed using RT PCR and nucleic acid sequencing. Serum dilutions were loaded into duplicate wells coated with infected cell and control lysates and incubated for 1 hour at room temperature before washing and the addition of conjugated rabbit antihuman IgG (Dako, Glostrup, Denmark) for 1 hour. Bound conjugate was detected using the colorigenic substrate $o$-phenylenediamine and hydrogen peroxide; the reaction was stopped with $2 \mathrm{M}$ sulphuric acid. The absorbance was read at $490 \mathrm{~nm}$ wavelength with $650 \mathrm{~nm}$ as the reference wavelength. The mean $\mathrm{OD}_{490}$ of the wells containing infected lysates minus the

Table 1 Immunoglobulin $G$ subclass determination in a patient with Nipah encephalitis

\begin{tabular}{llllll}
\hline IgG subclass & $\begin{array}{l}\text { CSF April } \\
\text { 1999 }\end{array}$ & $\begin{array}{l}\text { Serum April } \\
1999\end{array}$ & $\begin{array}{l}\text { Serum May } \\
1999\end{array}$ & $\begin{array}{l}\text { Serum October } \\
1999\end{array}$ & $\begin{array}{l}\text { Serum August } \\
1999\end{array}$ \\
\hline IgG1 & + & + & ++ & + & + \\
IgG2 & - & - & - & - & - \\
IgG3 & - & - & + & - & - \\
IgG4 & - & - & - & - & - \\
\hline
\end{tabular}

$\mathrm{OD}_{490}$ of the control wells containing uninfected cell lysates was determined to be the adjusted $\mathrm{OD}_{490}$. The patient's acute CSF and serum samples from April were both positive for IgG against Nipah virus when tested at 1:100 dilution, with $\mathrm{OD}_{490}$ of 0.6 and 2.4 respectively. The second serum sample taken 2 weeks after admission showed that a clear IgG seroconversion had occurred (fig 1). IgG remained high 12 months after the illness. Serum samples from her sisters and mother were negative. An acute serum sample submitted to the Nipah virus task force in Kuala Lumpur was also reported to be positive for IgG antibodies against Hendra virus, but was negative for IgM.

It was not possible to develop an $\operatorname{IgM}$ capture ELISA for detection of Nipah virus specific IgM due to lack of suitable containment facilities for generating hyperimmune antisera. We therefore used the indirect ELISA to test for the presence of Nipah virus specific IgG subclasses using mouse monoclonal antibodies against IgG1, IgG2, IgG3, and IgG4 (Oxoid, Baskingstoke, Hants, UK). The bound monoclonal antibodies were detected using a rabbit antimouse IgG HRP (Dako, Glostrup, Denmark). Nipah virus specific IgG1 was detected in all serum specimens and in the CSF (table 1). IgG3 was negative in the CSF and first serum sample, but was positive in serum 2 weeks later. IgG2 and IgG4 were not detected.

\section{Discussion}

The 1998 epidemic of encephalitis in Malaysia started in Ipoh, in the north, and soon spread among pig farming communities across the country. Being a major pig farming area, Negeri Sembilan was severely affected. Although Japanese encephalitis was initially suspected, the fact that pigs were also sick, and that most victims were adults in contact with pig secretions made it unlikely..$^{10} \mathrm{~A}$ virus isolated from a patient's CSF was shown to be a paramyxovirus similar to Hendra virus, which affected humans and horses in Australia. ${ }^{9}$ It was subsequently named Nipah virus, after Sungai Nipah town, where the patient came from. More than 265 people, ranging from 13 to 68 years old, were infected with Nipah virus, with at least 105 deaths (Source: Ministry of 
Health, Government of Malaysia). Many had direct contact with pigs in the 2 weeks before the onset of illness. Most patients with Nipah encephalitis presented with acute neurological features, which included a reduced level of consciousness, myoclonus, areflexia, hypotonia, and cerebellar signs. ${ }^{36} \mathrm{~A}$ delay of up to 11 weeks has been reported between initial exposure and neurological disease, although a second exposure was possible. ${ }^{41}$

We think that our patient, one of the youngest recorded with Nipah encephalitis, became exposed to the virus in December 1998, around the same time as her father. Because she left peninsular Malaysia for Sarawak, which was free of Nipah virus, we can be certain that the interval of 4 months represents a true late presentation between rather than a reexposure. Similarly, one of the three human cases of Hendra encephalitis occurred 13 months after the initial exposure, ${ }^{3}$ and measles virus, another paramyxovirus, causes subacute sclerosing panencephalitis many years after initial exposure. ${ }^{12} 13$ The IgM capture ELISA and indirect IgG ELISA against Hendra virus used during the Nipah outbreak in 1998 were positive in serum samples of about $70 \%$ of patients, and CSF of about $30 \% .^{414}$ The indirect IgG ELISA against Nipah antigen that we developed was positive in both serum and CSF. Interestingly although our patient's IgG was high when she first presented in April 1999, titres rose even higher during the next 2 weeks. The detection of IgG3 as well as IgG1 in Nipah virus infection is similar to the IgG subclass responses seen in measles and subacute sclerosing panencephalitis. ${ }^{15}$ Unfortunately no specimens were taken during her original febrile illness in December 1998, but by comparison with other Nipah patients we expect her IgM would have been positive then. The reason for the late presentation of Nipah virus is not known. For subacute sclerosing panencephalitis there is some evidence that defective measles virus particles which replicate poorly within the CNS provide a chronic stimulus to the immune system, resulting in inflammation and tissue destruction. ${ }^{13}$

In summary, Nipah virus encephalitis may present late, and should be considered in people with encephalitis, even months after their possible exposure. An indirect IgG ELISA can be used to confirm the diagnosis.

We thank the Director General of Health, Ministry of Health of Malaysia for granting us permission to publish this paper. We are also grateful to Dr Flora Ong, Dr K. Krishnan, Sister Margaret Wong and her team at the Sibu Health Department, and the Hospital Director for supporting the work. Dr Norain Karim, pathologist of Ipoh Hospital, provided the clinical material from which MJC isolated the strain of Nipah virus used in this work. TS is a Wellcome Trust Career Development Fellow.

1 Anonymous. Outbreak of Hendra-like virus: Malaysia and Singapore, 1998-9. MMWR Morb Mortal Wkly Rep 1999;48:265-9

2 Chua KB, Goh KJ, Wong KT, et al. Fatal encephalitis due to Nipah virus among pig-farmers in Malaysia. Lancet 1999;354:1257-9.

3 O'Sullivan J, Allworth AM, Paterson DL, et al. Fatal encephalitis due to a novel paramyxovirus transmitted from horses. Lancet 1997;349:93-5.

4 Goh KJ, Tan CT, Chew NK, et al. Clinical features of Nipah virus encephalitis among pig farmers in Malaysia. $N$ Engl $\mathcal{F}$ Med 2000;342:1229-35.

5 Paton NI, Leo YS, Zaki SR, et al. Outbreak of Nipah-virus infection among abattoir workers in Singapore. Lancet infection among

1999;354:1253-6.
6 Lee KE, Umapathi T, Tan CB, et al. The neurological Lee KE, Umapathi $\mathrm{T}$, Tan CB, et al. The neurological
manifestations of Nipah virus encephalitis, a novel paramyxovirus. Ann Neurol 1999;46:428-32.

7 Solomon T, Thao LTT, Dung NM, et al. Rapid diagnosis of Japanese encephalitis by using an IgM dot enzyme immunoassay. F Clin Microbiol 1998;36:2030-4.

8 Cardosa MJ, Krishnan S, Tio PH, et al. Isolation of subgenus $\mathrm{B}$ adenovirus during a fatal outbreak of enterovirus 71-associated hand, foot, and mouth disease in Sibu, Sarawak. Lancet 1999;354:987-91.

9 Chua KB, Bellini WJ, Rota PA, et al. Nipah virus: a recently emergent deadly paramyxovirus. Science 2000;288:1432-5.

10 Farrar J. Nipah-virus encephalitis: investigation of a new infection. Lancet 1999;354:1222-3.

11 Sarii SA, Abdullah BJ, Goh KJ, et al. MR imaging features of Nipah encephalitis. AfR Am $\mathcal{f}$ Roentgenol 2000;175:43742 .

12 Brooks BR, Jubelt B, Swarz JR, et al. Slow viral infections. Ann Rev Neurosci 1979;2:310-40.

13 Houff SA. Subacute sclerosing panencephalitis. In: Gilman S, Goldstein GW, Waxman SG, eds. Neurobase, 1st 2001 ed. San Diego: Medlink, 2001

14 Daniels P, Ksiazek T, Eaton BT. Laboratory diagnosis of Nipah and Hendra virus infections. Microbes Infect 2001;3: 289-95.

15 Narita M, Yamada S, Matsuzono Y, et al. Measles virus-specific immunoglobulin $G$ subclass response in serum and cerebrospinal fluid. Clin Diagn Virol 1997;8: $233-9$ 